\title{
Bench Scale Generation of Smoke Particulates and Hydrocarbons from Burning Polymers
}

\author{
ANNA A. STEC, and JENNIFER RHODES \\ Centre for Fire and Hazard Science \\ University of Central Lancashire \\ Preston, Lancashire, PR1 2HE, UK
}

\begin{abstract}
The soot and hydrocarbon generation behaviour from four common polymers has been investigated under different fire conditions using different bench scale apparatuses. While well-ventilated flaming typically has high $\mathrm{CO}_{2} / \mathrm{CO}$ ratios and high combustion efficiency, in under-ventilated flaming, higher yields of the many products of incomplete combustion are generally observed, including carbon monoxide, soot and hydrocarbons.

Hydrocarbon and soot production from polyethylene, polystyrene, polyamide and polyvinyl chloride were investigated using the steady state tube furnace (ISO TS 19700) under well-ventilated, small underventilated and large under-ventilated fire conditions; and in the smoke density chamber (ISO 5659-2) under the three standard test conditions; and the results have been compared to published data from the fire propagation apparatus (ASTM E 2058). The steady state tube furnace and the fire propagation apparatus show good agreement, for hydrocarbon and soot yields. Conversely it proved impossible to identify correlations with these tests for the soot and hydrocarbon yields in the smoke density chamber.

To investigate the soot generation further, the particle size distribution was determined using a cascade impactor. This showed the predominance of $1-5 \mu \mathrm{m}$ particulates for all polymers, except PVC, in underventilated conditions, and a smaller yield and a more even particle size distribution for well-ventilated burning. For PVC, no significant difference was observed for different fire conditions, with no clear trend of particle size distribution.
\end{abstract}

KEYWORDS: smoke, soot, hydrocarbon, equivalence ratio, fire propagation apparatus, smoke density chamber, steady state tube furnace.

\section{INTRODUCTION}

The combustion conditions replicated by a physical fire model have a significant influence on the production of different fire effluents [1]. The yield and nature of the fire effluents are a function of the fuels involved and the prevailing thermal and oxidative conditions of fire stages [2,3]. The yields of combustion products in a bench-scale method also depend on apparatus conditions, such as the fuel/air equivalence ratio $(\phi)$ or $\mathrm{CO}_{2} / \mathrm{CO}$ ratio, whether the decomposition is flaming or non-flaming, the temperature of the specimen and the effluents produced, the stability of the decomposition conditions etc.

Most bench-scale methods used for toxicity testing are designed to reproduce a single fire stage or combustion condition, where real-scale fires simultaneously involve different fire stages in different places, which are changing with time [4]. These methods can be grouped according to their physical arrangement; from closed tests, such as those based on the smoke chamber, and flow through tests, such as the stationary and steady state tube furnaces, to the fire propagation apparatus. Alternatively, the methods can be grouped as those with constant combustion conditions, often achieving a prolonged steady-state period, and those with non-constant combustion conditions. Those with constant combustion conditions are best suited to producing data suitable for comparison and modelling, such as the ISO steady state tube furnace method (ISO TS 19700). Other bench-scale methods have non-constant combustion conditions, such as those in closed or semi-closed chambers exposed to a constant source of heat, including the NBS smoke chamber (ISO 5659). Intermediate between these two extremes are those that can produce partially constant combustion conditions such as the fire propagation apparatus (ASTM E 2058). While the simpler tests are used to set pass/fail criteria for materials and products, there is a clear requirement from fire safety engineering to produce data which can be used as input to predictive models of smoke and fire toxicity $[4,5]$. 
The stages of a fire, from non-flaming, to well-ventilated flaming, and finally to under-ventilated flaming, have been classified by ISO (Table 1) in terms of heat flux, temperature, oxygen concentration, $\mathrm{CO}_{2}$ to $\mathrm{CO}$ ratio, combustion efficiency and equivalence ratio $\phi$ (the actual fuel-to-air ratio divided by the stoichiometric fuel-to-air ratio) [6]. While some real life fires may be represented by a single fire stage, other fires may pass through several different stages [7].

Table 1. ISO classification of fire stages, based on ISO 19706 [7].

\begin{tabular}{|c|c|c|c|c|c|c|c|}
\hline \multirow[t]{2}{*}{ Fire stage } & \multirow{2}{*}{$\begin{array}{c}\text { Heat } \\
\left(\mathrm{kW} / \mathrm{m}^{2}\right)\end{array}$} & \multicolumn{2}{|c|}{ Max. temp. $\left({ }^{\circ} \mathbf{C}\right)$} & \multicolumn{2}{|c|}{ Oxygen (\%) } & \multirow{2}{*}{$\begin{array}{c}\text { Equiv- } \\
\text { alence } \\
\text { ratio } \\
\phi\end{array}$} & \multirow{2}{*}{$\frac{\mathrm{V}_{\mathrm{CO}}}{\mathrm{V}_{\mathrm{CO}_{2}}}$} \\
\hline & & Fuel & Smoke & In & Out & & \\
\hline \multicolumn{8}{|l|}{ Non-flaming } \\
\hline 1a. Self sustained smouldering & n.a. & $450-800$ & $25-85$ & 20 & $0-20$ & - & $0.1-1$ \\
\hline 1b. Oxidative, external radiation & - & $300-600$ & & 20 & 20 & - & \\
\hline \multicolumn{8}{|l|}{ Well-ventilated flaming } \\
\hline 2. Well-ventilated flaming & $0-60$ & $350-650$ & $50-500$ & $\sim 20$ & $0-20$ & $<1$ & $<0.05$ \\
\hline \multicolumn{8}{|l|}{ Under-ventilated flaming } \\
\hline 3a. Small under-ventilated & $0-30$ & $300-600$ & $50-500$ & $15-20$ & $5-10$ & $>1$ & $0.2-0.4$ \\
\hline 3b. Large under-ventilated & $50-150$ & $350-650$ & $>600$ & $<15$ & $<5$ & $>1$ & $0.1-0.4$ \\
\hline
\end{tabular}

The use of $\mathrm{CO} / \mathrm{CO}_{2}$ ratios can only be used to characterise fire stages for materials which do not contain chlorine or bromine since these elements significantly increase the CO yield in well-ventilated fires [6].

\section{EXPERIMENTAL}

In this paper, smoke and hydrocarbon yields are compared from different bench-scale methods and compared with results obtained from the large scale. This paper compares smoke and hydrocarbon yields obtained using a standard fire toxicity assessment, in the steady state tube furnace (BS7990 [8] and ISO TS 19700 [9]), together with NBS smoke chamber, (ISO 5659-2 [10]), with published data from the fire propagation apparatus [11] (taken from Tewarson's [12] formulae for the prediction of toxic product yields as a function of equivalence ratio).

\section{Materials}

Four classes of polymeric materials were used in these studies:

- Low density polyethylene (LDPE) (Cleaflex, Polimeri Europa)

- Polystyrene (PS) (Atofina GPPS 1540)

- Nylon 6.6 (PA 6.6) (Invista)

- Polyvinyl chloride (PVC) (Doeflex-Vitapol).

The materials were selected to provide a range of different toxic products, showing different yield behaviour as a function of equivalence ratio or $\mathrm{CO}_{2} / \mathrm{CO}$ ratio. 


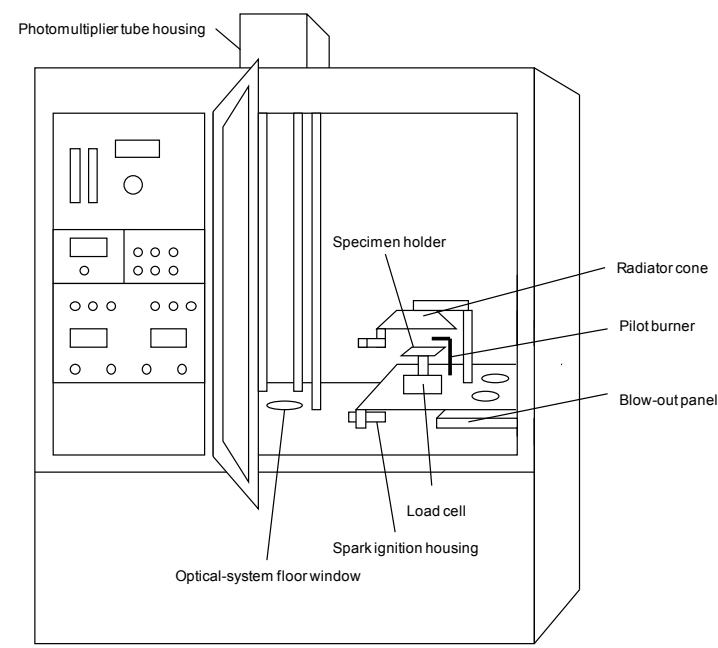

(a)

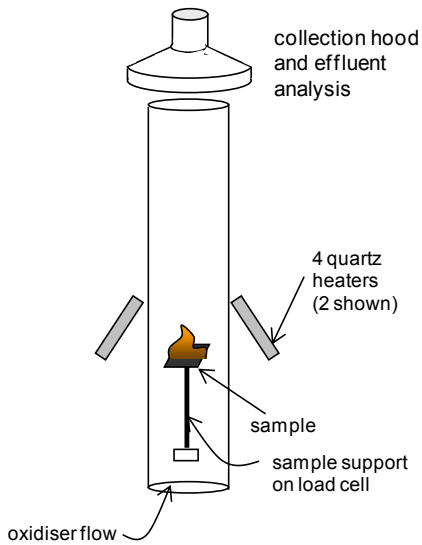

(b)

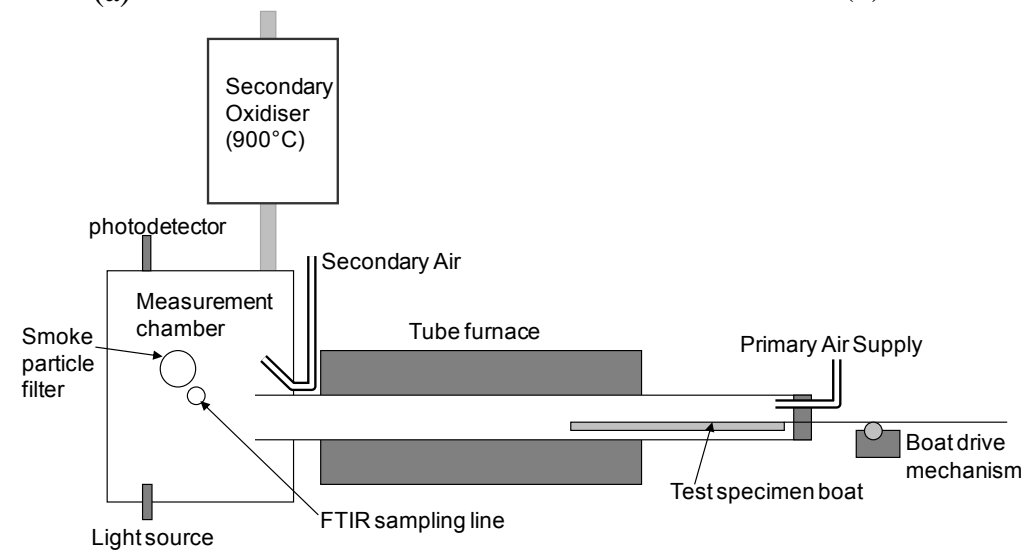

(c)

Fig. 1. Test methods used in these studies: (a) NBS smoke chamber; (b) fire propagation apparatus; (c) steady state tube furnace.

\section{The NBS Smoke Density Chamber - ISO 5659-2}

The smoke chamber [10,13-15], Fig. 1a, is a well-established piece of equipment, designed to monitor the smoke evolution from burning materials, in order to quantify visual obscuration during a fire. Visual obscuration is measured using a lamp and photodetector at the bottom and top of the chamber, respectively. The method defines smoke generation under flaming (with pilot burner) and non-flaming (without pilot burner) modes, which are reported as the average of the maximum specific optical densities (Table 2) $[10,16,17]$.

Decomposition takes place inside the closed cabinet of volume $0.51 \mathrm{~m}^{3}$. In all of these tests, the specimens, $75 \mathrm{~mm}$ square and up to $25 \mathrm{~mm}$ thick, were exposed to radiant heat (at $25 \mathrm{~kW} / \mathrm{m}^{2}$ or $50 \mathrm{~kW} / \mathrm{m}^{2}$ heat flux respectively) with and without a pilot flame. During the test fire stages may change from 2 to $3 a$ or $3 b$ (see also Table 3) [5]. The flaming fire stage for $25 \mathrm{~kW} / \mathrm{m}^{2}$ irradiation with pilot burner mode may be related between ISO stage 2 (well-ventilated) and stage $3 \mathrm{a}$ (small under-ventilated). The test at $50 \mathrm{~kW} / \mathrm{m}^{2}$ irradiation could possibly represent stage $3 b$ (post-flashover flaming) [18].

Three sets of conditions were employed for each polymer using different irradiation conditions, $25 \mathrm{~kW} / \mathrm{m}^{2}$ without pilot flame, $25 \mathrm{~kW} / \mathrm{m}^{2}$ with pilot flame, and $50 \mathrm{~kW} / \mathrm{m}^{2}$ without pilot flame. Before each test samples were conditioned for $24 \mathrm{~h}$ at a temperature of $23 \pm 3{ }^{\circ} \mathrm{C}$ and relative humidity $50 \pm 5 \%$ according to ISO 5659-2 test [10]. The gas samples were taken from the NBS smoke density chamber at the time when the maximum optical density was obtained (and determined in preliminary runs) for the burning 
polymeric material in order to quantify the products of incomplete combustion using a secondary combustion furnace [4,5].

Table 2. ISO Fire stages represented by NBS smoke density chamber [4].

\begin{tabular}{|c|c|c|}
\hline $\begin{array}{l}\text { Heat flux } \\
\left(\mathrm{kW} / \mathrm{m}^{2}\right)\end{array}$ & Pilot flame & $\begin{array}{c}\text { ISO fire stage } \\
\text { Depends on test material and thickness and on test duration. }\end{array}$ \\
\hline 25 & No & 1b) Oxidative pyrolysis from external radiation \\
\hline 25 & Yes & 2) Well-ventilated flaming to 3a) Small, Under-Ventilated flaming \\
\hline 50 & No & 3b) Large Under-Ventilated \\
\hline
\end{tabular}

\section{Fire Propagation Apparatus - ASTME E 2058}

In the fire propagation apparatus (FPA) [11], Fig. 1b, the fire zone is contained within a $172 \mathrm{~mm}$ diameter vertical silica tube, allowing better control of the fire atmosphere, and keeping it out of contact with the heaters, which are outside the tube. The effluent flows through an instrumented duct and the rate of heat release is determined from oxygen consumption and the effluent yields can be directly related to the ISO fire stages. A significant advantage of this method is that the air flow and composition in the fire zone is controlled and consequently the apparatus could be used with pre-determined values of equivalence ratio $(\phi)$ to generate effluent yield data for the different ISO fire stages [12,18-20].

\section{Steady State Tube Furnace - ISO TS 19700}

The steady state tube furnace method (SSTF), Fig. 1c, is used in the generation of fire effluent for the identification and measurement of its constituent combustion products, in particular, the yield of different fire effluents under a range of fire conditions according to standards: BS 7990 [8], and ISO TS 19700 [9]. This test was designed to replicate real fire conditions, by using a range of different temperatures and airflow rates [21]. It is possible to reproduce all the different fire stages and types, including lowtemperature non-flaming oxidative decomposition, well-ventilated flaming $(\phi<0.75)$ and hightemperature under-ventilated flaming decomposition conditions $(\phi>2)[22]$.

Table 3. Fire conditions corresponding to characteristic stages of burning behaviour.

\begin{tabular}{|c|c|c|c|}
\hline$\phi=\frac{\begin{array}{c}\text { Fire type defined by } \\
\text { equivalence ratio: } \\
\text { actual fuel to air ratio }\end{array}}{\text { stoichiom dric fuel to air ratio }}$ & $\begin{array}{l}\text { Temperature } \\
\left({ }^{\circ} \mathrm{C}\right)\end{array}$ & Fire type & $\begin{array}{c}\text { Primary air flow } \\
(\mathrm{L} / \mathrm{min})\end{array}$ \\
\hline N/A & 350 & 1b) Oxidative pyrolysis & 2 \\
\hline$\phi<0.75$ & 650 & 2) Well ventilated flaming & $10^{\mathrm{a}}$ \\
\hline$\phi>1.50$ & 650 & $\begin{array}{l}\text { 3a) Small under-ventilated } \\
\text { flaming fires }\end{array}$ & $\begin{array}{c}\text { Twice stoichiometric } \\
\text { fuel/air ratio }\end{array}$ \\
\hline$\phi>1.50$ & 825 & $\begin{array}{l}\text { 3b) Fully developed under- } \\
\text { ventilated fires }\end{array}$ & $\begin{array}{c}\text { Twice stoichiometric } \\
\text { fuel/air ratio }\end{array}$ \\
\hline
\end{tabular}

${ }^{\text {a }}$ subject to verification of ventilation condition.

The sample is spread evenly along a long silica boat of $800 \mathrm{~mm}$ and fed into a tube furnace at a typical rate of $1 \mathrm{~g} \mathrm{~min}^{-1}$ with flowing air. As it enters the furnace, the temperature (and applied heat flux) increases until ignition occurs. Once the flame stabilises the apparatus forces combustion at fixed fuel feed rates and primary air flow rates. Secondary air is added in a mixing chamber to give a total gas flow of $50 \mathrm{~L} \mathrm{~min}^{-1}$. The use of a high secondary air flow usually permits the required gas samples to be taken during a single run. Smoke obscuration may also be determined. In addition to analysis of the gases specified in ISO 13344 $\left(\mathrm{CO}_{2}, \mathrm{CO}, \mathrm{O}_{2}, \mathrm{HCN}, \mathrm{NO}_{\mathrm{x}}, \mathrm{HCl}\right.$, etc. $)$ there is a requirement to determine the total hydrocarbons. This may be achieved by passing part of the air-diluted test effluent through a secondary combustion furnace to allow the determination of the products of incomplete combustion by using a secondary combustion furnace (secondary oxidiser) by further oxidation at $900{ }^{\circ} \mathrm{C}$ in excess air over silica wool. 


\section{RESULTS}

\section{Small-Scale Comparison - SSTF, FPA and NBS Smoke Chamber}

Figure 2 compares yields from the steady state tube furnace (SSTF) with predictions based on yields from the fire propagation apparatus (FPA). The relationships proposed by Tewarson $[12,20]$, based on results obtained using FPA for prediction of the yields of fire products as a function of the equivalence ratio, $\phi$, have been used to compare the yields of smoke and hydrocarbons for four polymers.

It can be seen that for the most of polymers the smoke yields from the SSTF results show good agreement with FPA predicted results. In Fig. 2a, the low smoke yield from LDPE is consistent in both apparatuses. There is a small increase with equivalence ratio from a yield of 0.06 to $0.1 \mathrm{~g} / \mathrm{g}$ for the large underventilated condition, and the FPA. For the small under-ventilated condition there is a decrease in smoke yield above $\phi=1.2$.

In Fig. $2 b$ for PS there is also good agreement between the two tests and fire conditions for well-ventilated flaming, but a more pronounced upward trend is observed in the FPA with under-ventilation. The lower smoke yields formed for PS in under-ventilated conditions in the SSTF are consistent with the lower CO yields reported [23].

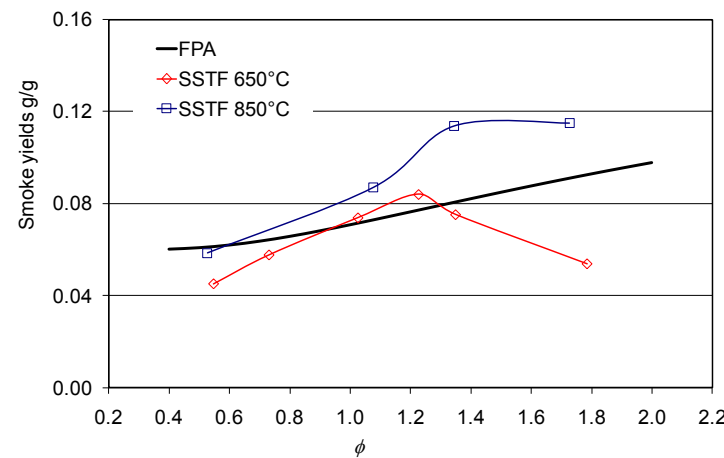

(a)

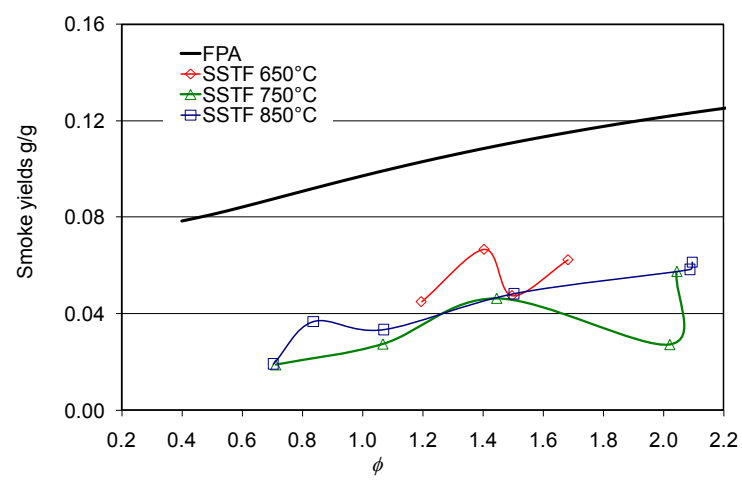

(c)

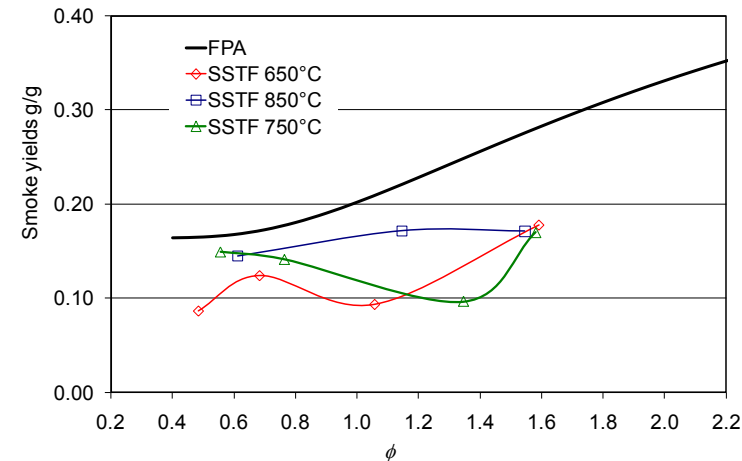

(b)

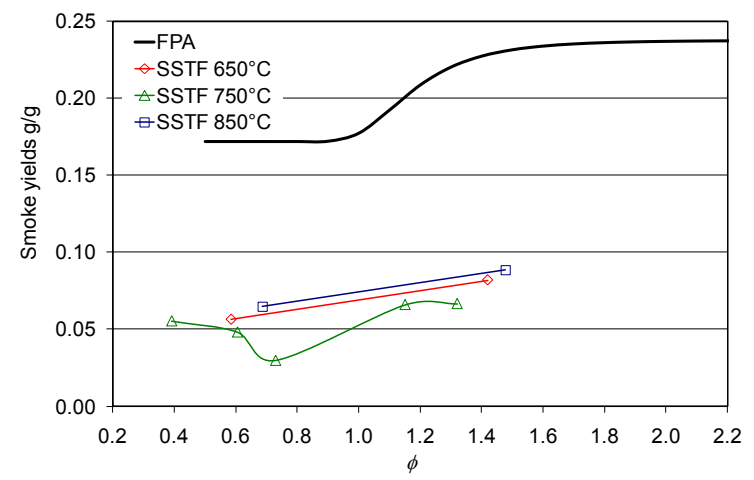

(d)

Fig. 2. Smoke yields comparison from the SSTF and FPA: (a) LDPE; (b) PS; (c) PA 6.6; (d) PVC.

Figure 2c shows a progressive increase in smoke yield with $\phi$, in both tests and at both conditions for PA 6.6. However, the smoke yields obtained in the FPA are typically double compared to those in the SSTF.

Figure $2 \mathrm{~d}$ shows greater variation in the smoke yields between the two tests, for PVC. It has previously been reported that the CO yields in the FPA for PVC differ markedly from those in the SSTF in wellventilated conditions [24]. This is believed to be an artefact of the FPA method, where initial mass loss from $\mathrm{PVC}$ is predominantly $\mathrm{HCl}$, giving an apparently low equivalence ratio, but where little fuel is actually evolved. 
The hydrocarbon yields from the different polymers show significant differences, as indicated by the different scaling on hydrocarbon axes in Fig. 3. In particular, PS and PVC show much lower hydrocarbon yields in under-ventilated conditions than LDPE or PA 6.6. For most polymers, except PVC, the Tewarson predictions show slightly larger hydrocarbon yields than those found in the SSTF.

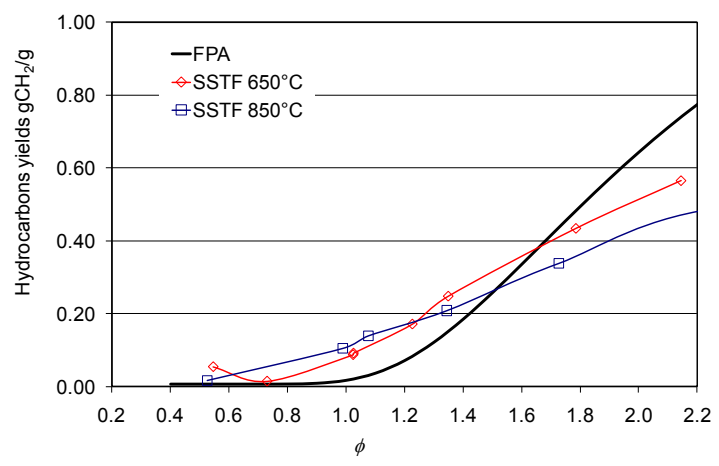

(a)

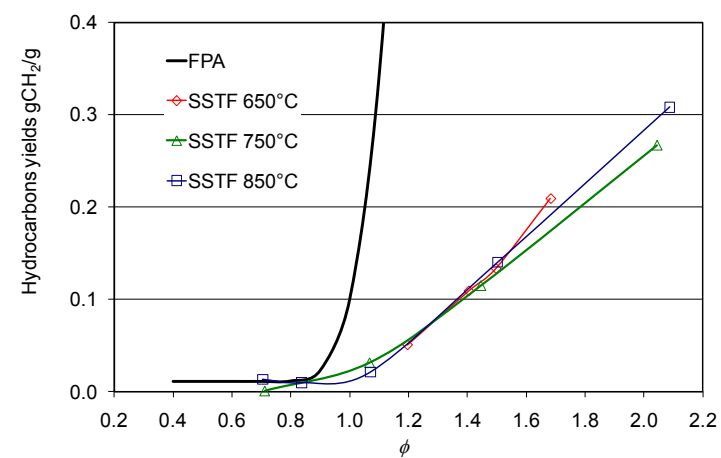

(c)

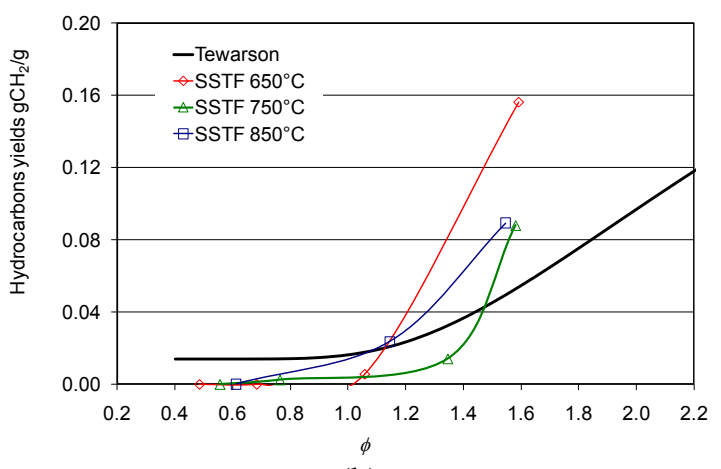

(b)

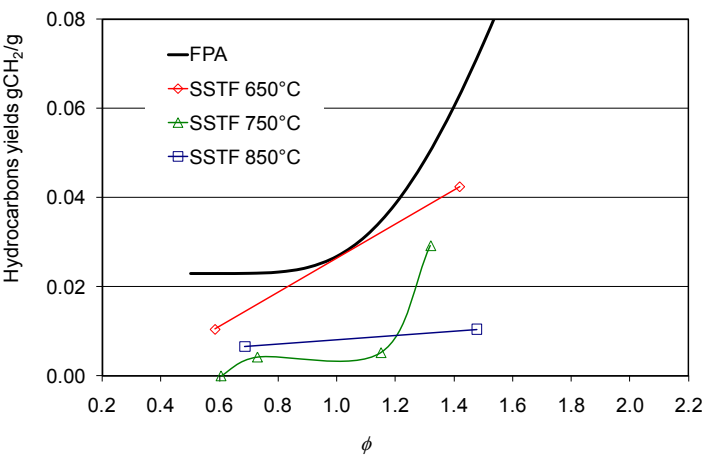

(d)

Fig. 3. Hydrocarbon yields comparison from the SSTF and FPA: (a) LDPE; (b) PS; (c) PA 6.6; (d) PVC.

Figure 3a shows very good agreement between the SSTF and FPA under both fire conditions for LDPE. The FPA indicates no hydrocarbon evolution until $\phi>1$, where the SSTF shows the hydrocarbon yield increasing as $\phi>0.7$.

Figure $3 b$ shows similarly good correspondence between the two tests for PS. In this case the SSTF shows a greater dependence on increase in equivalence ratio than the FPA.

Figure $3 \mathrm{c}$ shows very little dependence on furnace temperature for the increase in hydrocarbon yield for PA 6.6 in the SSTF. The FPA shows an even greater dependency on $\phi$, with hydrocarbon yields increasing rapidly when $\phi>0.9$.

Figure 3d shows reasonable agreement between the two tests for hydrocarbon evolution from PVC, but with almost double the actual yields being observed in the FPA compared to the SSTF.

The fire condition can also be characterised by its $\mathrm{CO}_{2} / \mathrm{CO}$ ratio (Table 1 and Table 2). The $\mathrm{CO}_{2} / \mathrm{CO}$ ratio is plotted as a function of hydrocarbon yield obtained from the SSTF; and the NBS smoke chamber, for oxidative pyrolysis $\left(25 \mathrm{~kW} / \mathrm{m}^{2}\right.$ without pilot) in Fig. 4 and for flaming conditions ( 25 and $50 \mathrm{~kW} / \mathrm{m}^{2}$ with the pilot burner), in Fig. 5. 


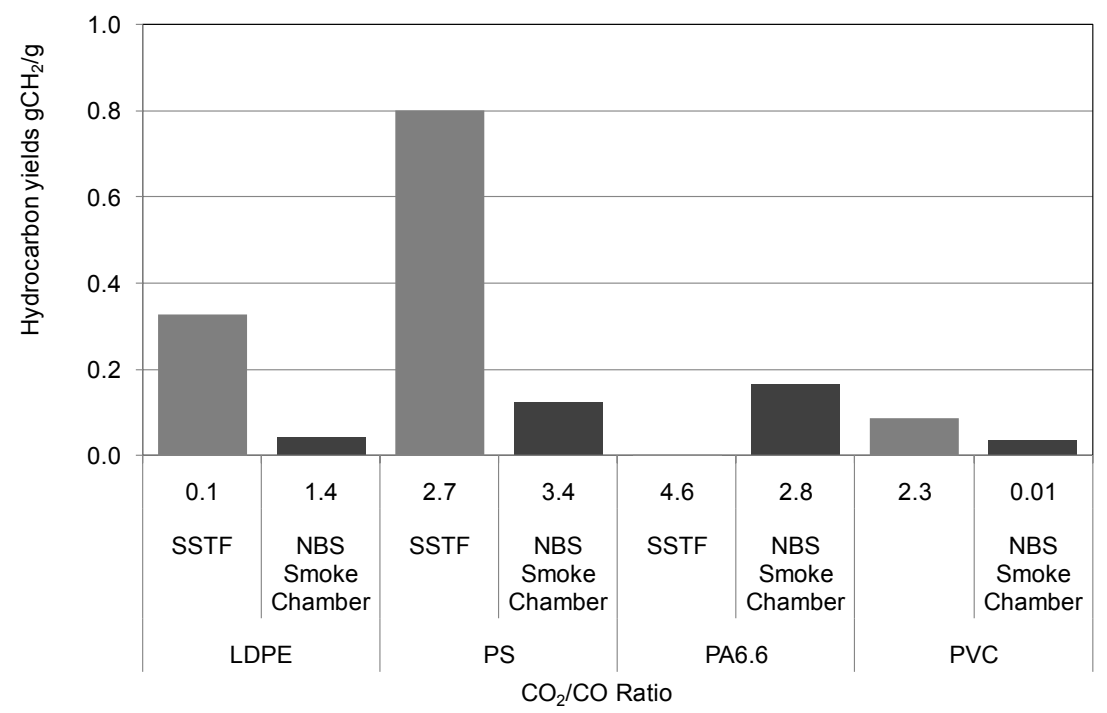

Fig. 4. Hydrocarbon yields comparison from the SSTF and NBS smoke density chamber for the oxidative pyrolysis conditions.

For LDPE samples, the hydrocarbon yield was found to be much more dependent upon combustion conditions, with the lowest yield being generated from $25 \mathrm{~kW} / \mathrm{m}^{2}$ without pilot burner, while almost 7 times more hydrocarbons were generated at $50 \mathrm{~kW} / \mathrm{m}^{2}$ with the pilot burner. For LDPE, the SSTF results show a significant increase between the hydrocarbon yield of well-ventilated burning and higher yields for underventilated fires. Good agreement is shown between hydrocarbons yields obtained in under-ventilated conditions from the NBS smoke density chamber and the SSTF.

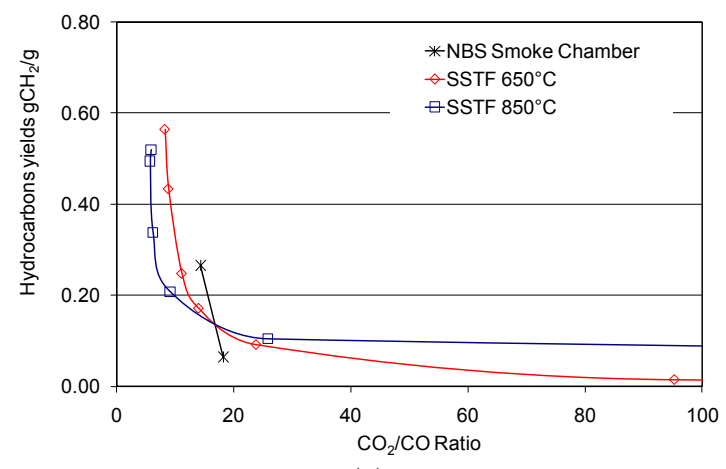

(a)

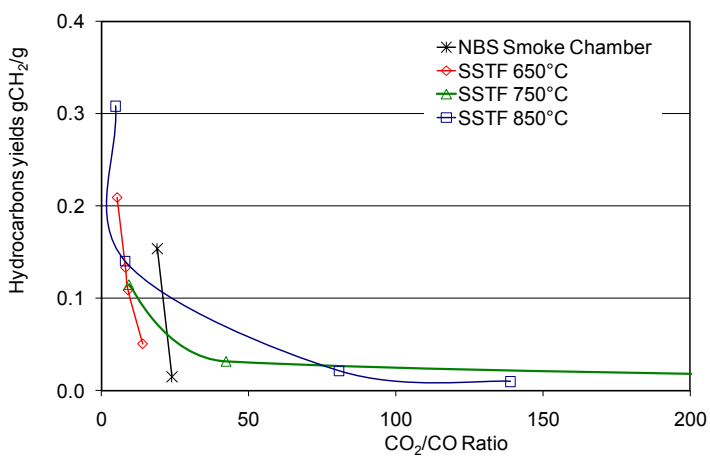

(c)

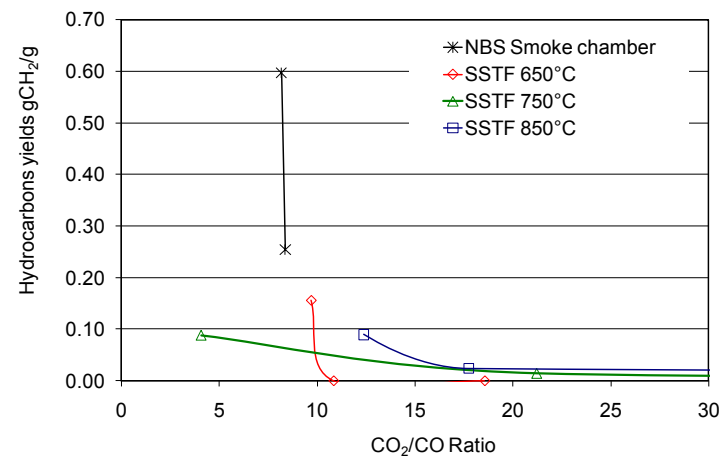

(b)

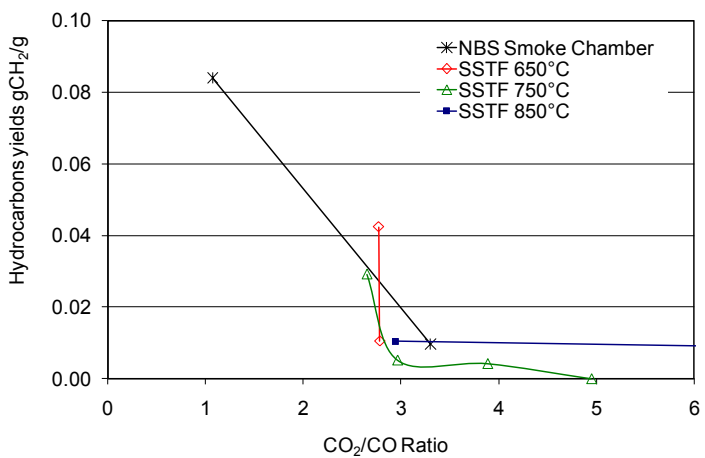

(d)

Fig. 5. Hydrocarbon yields comparison from the SSTF and NBS smoke density chamber under flaming conditions (25 and $50 \mathrm{~kW} / \mathrm{m}^{2}$ with the pilot burner): (a) LDPE; (b) PS; (c) PA 6.6; (d) PVC. 
The results for PS from the SSTF give the expected very low hydrocarbon yields under well-ventilated conditions, but high yields in under-ventilated conditions. For PS there is a very high level of organic species in the fire effluent obtained from the NBS smoke density chamber for both ventilation conditions. There is an anomaly between product yields in well-ventilated $\left(25 \mathrm{~kW} / \mathrm{m}^{2}\right.$ with pilot burner) and underventilated fire conditions $\left(50 \mathrm{~kW} / \mathrm{m}^{2}\right.$ with pilot burner).

In the case of PVC there is little difference between the hydrocarbon yields for the fire conditions in the SSTF. There is a significant increase in hydrocarbons yields between the well-ventilated and underventilated flaming conditions for the NBS smoke density chamber. In addition, there is an observed anomaly for the tests under $25 \mathrm{~kW} / \mathrm{m}^{2}$ with pilot burner where very low hydrocarbon yields are observed.

Similarly to PVC, for Nylon 6.6 all tests show a dramatic increase in hydrocarbon yield from $25 \mathrm{~kW} / \mathrm{m}^{2}$ to $50 \mathrm{~kW} / \mathrm{m}^{2}$ for the NBS smoke chamber. However a very similar trend to PVC is observed where the hydrocarbon yields under $25 \mathrm{~kW} / \mathrm{m}^{2}$ were very low. A consistent trend is observed between the low yields under well-ventilated combustion and the higher yields in under-ventilated combustion in the SSTF.

\section{Cascade Impactor}

In order to gain more insight into the formation and production of smoke, a cascade impactor was used to separate the particles by their aerodynamic diameters. It is one of the only techniques which provides a particle size distribution expressed in terms of mass (rather than number) of particles in each size range [25-27]. This is the most relevant parameter for predicting particle transport [28], and health hazard [29].

The cascade impactor was attached to the mixing chamber of the steady state tube furnace. Fire effluent was drawn through at a flow of 2.0 litres $\mathrm{min}^{-1}$ for a period of five minutes during the steady state, and aerosol mass distributions were determined.

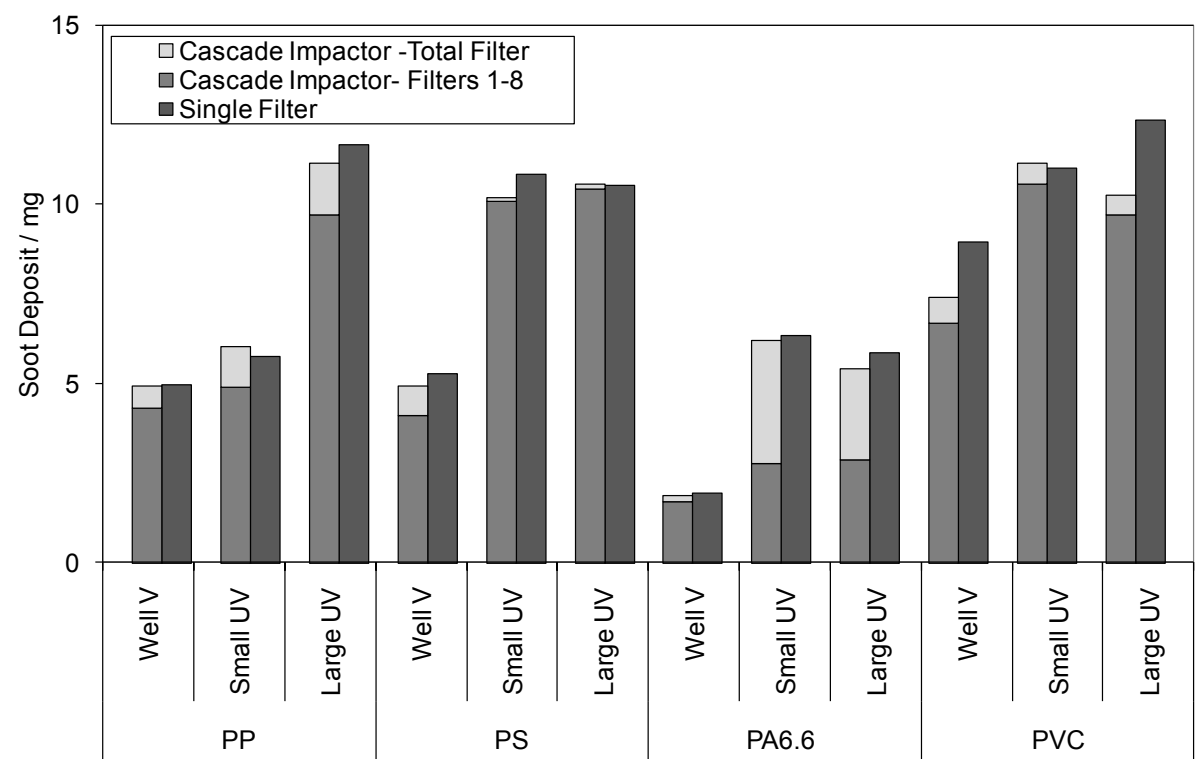

Fig. 6. Total mass of soot collected in the cascade impactor and on the filter for different polymers.

Results are compared for different polymers under various fire conditions in Fig. 6. In order to validate the data the total soot yield was compared to the total distribution of soot collected and separated by the cascade impactor. The cascade impactor total soot estimation was the sum of the soot collected at each stage and included the soot collected by a final porous paper filter. This is located at the end of the cascade impactor filter assembly and collects particles too small to be trapped onto any cascade impactor levels (smaller than $0.5 \mu \mathrm{m}$ ). This was compared to the total amount of soot on the filter paper taken from the mixing chamber, also with a flow of $2.0 \mathrm{~L} \mathrm{~min}^{-1}$ for five minutes during steady state burning.

The mass determined on the single filter shows good agreement with the total deposited on each of the cascade impactor filters, for each polymers under each fire condition. 
For LDPE, PS and PA 6.6 two distinctive patterns of behaviour are observed. In small and large underventilated tests there is a predominance of smaller soot particles $(1-5 \mu \mathrm{m})$ diameter. For PS and PA 6.6 the furnace temperature $\left(650\right.$ or $825^{\circ} \mathrm{C}$ ) seems to make little difference to the particle size distribution, where for LDPE the small under-ventilated condition shows intermediate behaviour between well-ventilated and large under-ventilated. In each case the soot yields are lower, and the particle size distribution is very different for the well-ventilated, where there is a more uniform distribution. The exception is PVC, where there is little difference between fire conditions, and no peak in the $1-5 \mu \mathrm{m}$ range. This is analogous to the higher $\mathrm{CO}$ yields under all ventilation conditions observed for $\mathrm{PVC}$, where the radical trapping by $\mathrm{HCl}$ prevents the conversion of $\mathrm{CO}$ to $\mathrm{CO}_{2}$ [30]. This implies that the presence of stable halogen radicals also influence the formation and particle size distribution of soot.

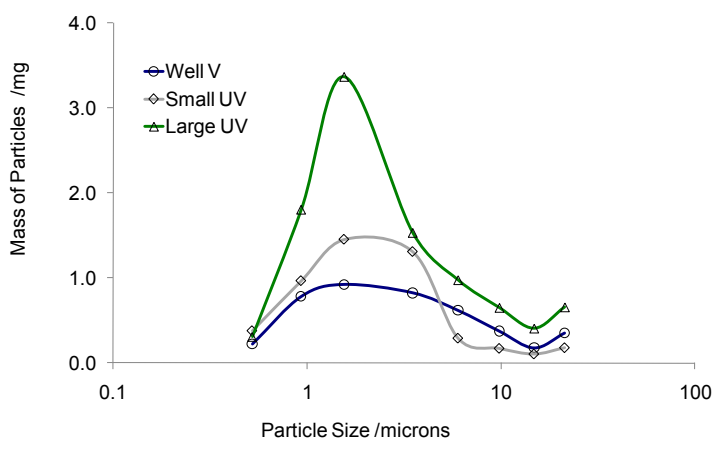

(a)

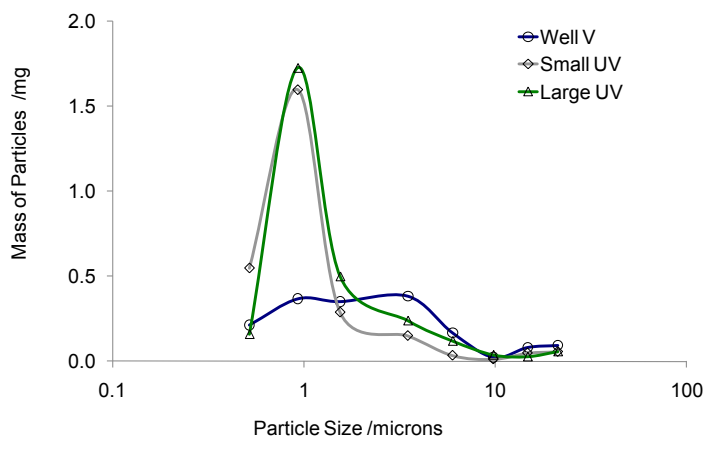

(c)

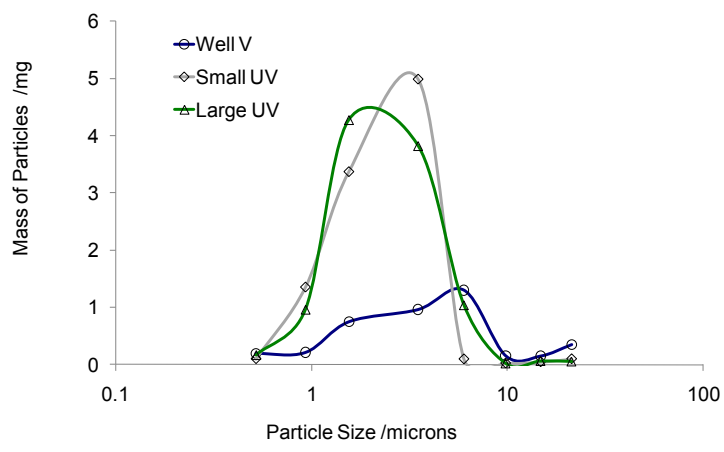

(b)

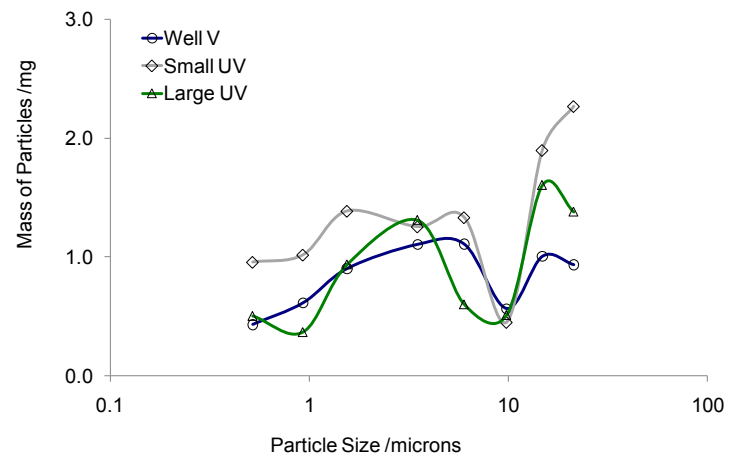

(d)

Fig. 7. Soot distribution for different polymers under various fire conditions: (a) LDPE; (b) PS; (c) PA 6.6; (d) PVC.

Figure 7 shows the mass of soot collected on each stage of the filter, expressed in terms of the particle size (or strictly the aerodynamic diameter) using a log scale on the $\mathrm{x}$-axis.

\section{CONCLUSIONS}

The predictions reported by Tewarson obtained in the fire propagation apparatus generally correspond well with SSTF, particularly showing similar trends with ventilation condition, but tending to predict slightly higher hydrocarbon yields. Poor agreement with PVC smoke yield in all conditions is believed to be an artefact of the FPA apparatus and particularly the method by which $\phi$ was calculated.

It is shown impossible to identify correlations with these tests for the smoke and hydrocarbon yields in the smoke density chamber for different polymers.

The particle size distribution data show two clear trends. For LDPE, PS and PA 6.6 there are clear differences between well-ventilated burning and under-ventilated burning, with a peek between 1-5 $\mu \mathrm{m}$ of some of the most dangerous particulates - those able to penetrate deep into the lung - in under-ventilated fires. The differences observed in PVC are intriguing, and given the similarity of behaviour with the independence of $\mathrm{CO}$ yield with fire condition suggests that similar mechanism may be involved. 


\section{ACKNOWLEDGMENTS}

Jennifer Rhodes would like to thank EPSRC for provision of a PhD studentship.

\section{REFERENCES}

[1] Stec, A.A. and Hull, T.R., Fire Toxicity, Woodhead Publishing, CRC Press, Cambridge, 2010, pp. $515-540$.

[2] ISO 16312-1: 2006 Guidance for Assessing The Validity of Physical Fire Models for Obtaining Fire Effluent Toxicity Data for Fire Hazard And Risk Assessment - Part 1: Criteria, 2006.

[3] Stec, A.A., and Hull, T.R., "Fire Effluent Toxicity: Yields and Effects From Common Materials Under Different Fire Conditions," Proceedings of the Sixth International Seminar on Fire and Explosion Hazards, D. Bradley (ed.), Leeds, UK, April 2010 (in press).

[4] Stec, A.A. and Hull, T.R., Fire Toxicity, Woodhead Publishing, CRC Press, Cambridge, 2010, pp. 424-458.

[5] Hull, T.R., and Paul, K.T., (2007) Bench-Scale Assessment of Combustion Toxicity - A Critical Analysis of Current Protocols, Fire Safety Journal 42: 340-365 http://dx.doi.org/10.1016/j.firesaf.2006.12.006.

[6] Stec, A.A. and Hull, T.R., Fire Toxicity, Woodhead Publishing, CRC Press, Cambridge, 2010, pp. 26-47.

[7] ISO TS 19706: 2004 Guidelines for Assessing the Fire Threat to People, 2004.

[8] BS 7990: 2003 Tube Furnace Method for the Determination of Toxic Product Yields in Fire Effluents, 2003.

[9] ISO TS 19700: 2006 Controlled Equivalence Ratio Method for the Determination of Hazardous Components of Fire Effluents, 2006.

[10] EN ISO 5659-2: 2006, Plastics - Smoke Generation - Part 2: Determination of Optical Density by a Single-Chamber Test, 2006.

[11] ASTM E 2058-02a Standard Test Methods for Measurement of Synthetic Polymer Material Flammability Using a Fire Propagation Apparatus (FPA), 2002.

[12] Tewarson, A., "Generation of Heat and Chemical Compounds in Fires," The SFPE Handbook of Fire Protection Engineering ( $3^{\text {rd }}$ ed), DiNenno P.J. (ed), National Fire Protection Association, Quincy, MA 02269, 2002, p. 3-82.

[13] EN ISO 5659-1: 1999 Plastics -Smoke Generation-Part 1: Guidance on Optical Density Testing, 1999.

[14] BS 6401:1983 Method for Measurement, in the Laboratory, of the Specific Optical Density of Smoke Generated by Materials, 1983.

[15] BS EN 60695-6-1: 2005 Fire Hazard Testing. Smoke Obscuration. General Guidance, 2005.

[16] BS 7904: 1998 Guide to Smoke Measurement Units -Their Basis and Use in Smoke Opacity Test Methods, 1998.

[17] Kourtides, D.A., and Roper, W.D., "Optimization of Aircraft Interior Panels," National Aeronautics and Space Administration, Ames Research Center, National Technical Information Service 22161, Springfield, Virginia, 1986.

[18] Hull, T.R., and Stec, A.A., "Fire Effluent Toxicity: Bench-Scale Generation of Toxic Products," Proceedings of the Sixth International Seminar on Fire and Explosion Hazards, D. Bradley (ed.), Leeds, UK, April 2010 (in press). 
[19] Stec, A.A., Hull, T.R., Lebek, K., Purser, J.A., and Purser, D.A., (2008) The Effect of Ventilation Condition on the Toxic Product Yields from Burning Polymers, Fire and Materials 32: 49-60, http://dx.doi.org/10.1002/fam.955.

[20] Tewarson, A., Jiang, F.H., and Morikawa, T., (1993) Ventilation Controlled Combustion of Polymers, Combustion and Flame 95: 151-69, http://dx.doi.org/10.1016/0010-2180(93)90058-B.

[21] Stec, A.A., Lebek, K., and Hull, T.R., (2008) Characterisation of the Steady State Tube Furnace (ISO TS 19700) for Fire Toxicity Assessment, Polymer Degradation and Stability 93: 2058-2065, http://dx.doi.org/10.1016/j.polymdegradstab.2008.02.020.

[22] Stec, A.A., Hull, T.R., Purser, J.A., Blomqvist, P. and Lebek, K., 2009. A Comparison of Toxic Product Yields Obtained from Five Laboratories Using the Steady State Tube Furnace (ISO TS 19700). Fire Safety Science 9: 653-664. http://dx.doi.org/10.3801/IAFSS.FSS.9-653.

[23] Hull, T. R., Carman, J. M., and Purser, D. A., (2000) Prediction of CO Evolution from SmallScale Polymer Fires, Polymer International 49: 1259-1265, http://dx.doi.org/10.1002/10970126(200010)49:10<1259::AID-PI573>3.3.CO;2-4.

[24] Hull, T.R., Lebek, K., Stec, A.A., Paul, K.T., and Price, D., "Bench-Scale Assessment of Fire Toxicity," Advances in the Flame Retardancy of Polymeric Materials: Current perspectives, FRPM'05 Ed. B. Schartel, Herstellung und Verlag, Norderstedt, 2007, pp.235-248.

[25] Gwaze, P., Annegarn, H.J., Huth, J., and Helas, G., (2007) Comparison of Particle Sizes Determined with Impactor, AFM and SEM, Atmospheric Research 86: 93-104, http://dx.doi.org/10.1016/j.atmosres.2007.02.009.

[26] Pilcer, G., Vanderbist, F., and Amighi, K., (2008) Correlations Between Cascade Impactor Analysis and Laser Diffraction for the Determination of the Particle Size of Aerosolised Powder Formulations, International Journal of Pharmaceutics 358: 75-81, http://dx.doi.org/10.1016/j.ijpharm.2008.02.014.

[27] Hertzberg, T., and Blomqvist, P., (2003) Particles from Fires - A Screening of Common Materials Found in Buildings, Fire and Materials 27: 295-314, http://dx.doi.org/10.1002/fam.837.

[28] Majoral, C., Pape, A.L., Diot, P., and Vecellio, L., (2006) Comparison of Various Methods for Processing Cascade Impactor Data, Aerosol Science and Technology 40: 672-682, http://dx.doi.org/10.1080/02786820600796582.

[29] OECD Environment, Health and Safety Publications, Series on Testing and Assessment, "Guidance Document on Acute Inhalation Toxicity Testing", Environment Directorate Organisation for economic co-operation and development, No. 39, Paris 2009.

[30] Hull, T.R., Stec, A.A. and Paul, K.T., 2009. Hydrogen Chloride in Fires. Fire Safety Science 9: 665-676. http://dx.doi.org/10.3801/IAFSS.FSS.9-665. 